Article

\title{
Research on the Re-Deformation Characteristics of Hot Stamping of Boron Steel Parts with Tailored Properties
}

\author{
Ling Kong * ${ }^{\mathbb{D}}$, Yan Peng and Caiyi Liu \\ National Engineering Research Center for Equipment and Technology of Cold Strip Rolling, Yanshan University, \\ Qinhuangdao 066004, China; pengyan@ysu.edu.cn (Y.P.); caiyi.liu@outlook.com (C.L.) \\ * Correspondence: kongling@ysu.edu.cn; Tel.: +86-0335-838-7652
}

Received: 21 July 2020; Accepted: 12 August 2020; Published: 24 August 2020

check for updates

\begin{abstract}
Traditional hot-stamping products have super-high strength, but their plasticity is usually low and their integrated mechanical properties are not excellent. Functionally graded property structures, a relatively novel configuration with a higher material utilization rate, have increasingly captured the attention of researchers. Hot stamping parts with tailored properties display the characteristics of local high strength and high plasticity, which can make up for the limitations of conventional hot stamping and optimize the crash safety performance of vehicles. This new idea provides a means of personalized control in the hot-stamping process. In this paper, a new strategy of local induction heating and press hardening was used for the hot stamping of boron steel parts with tailored properties, of which the microstructure from the hard zone to the soft zone shows a gradient distribution consisting of a martensite phase, multiphase and initial phase, with the hardness ranging from $550 \mathrm{HV}$ to $180 \mathrm{HV}$. The re-deformation characteristics of hot stamping parts with tailored properties have been studied through the uniaxial tensile test, in cooperation with digital image correlation (DIC) and electron backscattered diffraction (EBSD) techniques. The experiments show that there are easily observable strain distribution characteristics in the re-deformation of hot stamping parts with tailored properties. In the process of tensile deformation, the initial phase zone takes the role of deformation and energy absorption, with the maximum strain before necking reaching 0.32 . The local misorientation of this zone was high, and a large number of low angle grain boundaries were formed, while the proportion of small angle grain boundaries increased from $13.5 \%$ to $63.3 \%$, and the average grain size decreased from $8.15 \mu \mathrm{m}$ to $3.43 \mu \mathrm{m}$. Meanwhile, the martensite zone takes on the role of anti-collision protection, with a maximum strain of only 0.006 , and its local misorientation is mostly unchanged. The re-deformation experimental results show that the hot stamping of boron steel parts with tailored properties meets the functional requirements of a hard zone for anti-collision and a soft zone for energy absorption, suitable for automobile safety parts.
\end{abstract}

Keywords: re-deformation characteristics; hot stamping; tailored properties; boron steel

\section{Introduction}

Press-hardening steels (PHS) are steel plates with the highest strength grade of all automobile plates. They are increasingly used for vehicle body structure components, such as door crash beams, front and rear bumpers, B-pillars, etc., because of their lightening potential, owing to superior strength, small springback and high yield. The proportion of their application in car bodies is increasing [1,2]. At present, the most commonly used PHS is 22MnB5 steel, which displays a tensile strength of up to 1500-1800 MPa and an elongation of 5-7\% by hot stamping. However, the problem of high strength and low plasticity has been observed in the process of hot-stamping parts, which makes it difficult to 
achieve the best matching of the hardness and energy absorption in the service process, and affects the safety performance of vehicle parts under the impact of collision. The hot stamping of parts with tailored properties is a relatively novel approach, with a higher material utilization rate and better material-bearing potential, which has increasingly captured the attention of researchers. [3,4]. In this process, different areas of parts can have different properties matched with the use requirements. The hot stamping of parts with tailored properties can better balance the rigidity, torque and impact energy absorption effect of the body, while reducing the weight and making up for the limitations of the uniformity of conventionally hot-stamped parts, thus providing a new means of personalized control in hot stamping [5].

Marked by the "tailored tempering" technology of ThyssenKrupp, tailored hot-stamping technology has entered a stage of rapid development, and various new process variants based on traditional hot stamping have been introduced lately. The intrinsic strategy, composed of differential temperature heating, the differential cooling rate method and secondary annealing is the main approach used to produce parts with tailored properties, thus changing the microstructure of components using specifically-arranged strategies of cooling or annealing [6]. Wilsius et al. [7] achieved the trial production of a performance gradient B-pillar with a tensile strength of $1600 \mathrm{MPa}$ in the hard zone and $700 \mathrm{MPa}$ in the soft zone by partial austenitizing in the hot stamping. MU et al. [8,9] made $\mathrm{M}$-shaped parts with varying properties by hot stamping using partition heating, and studied the effects of hot stamping parameters such as stamping velocity and heating temperature on the formation and mechanical properties of the tailored M-shaped part. Furthermore, multi-objective optimization was performed using the non-dominated sorting genetic algorithm II to obtain the optimal heating parameters. Svec et al. [10] also prepared the gradient hardness parts with the hardness of heating area ranging from 200-240 HV and the hardness of the hard area at about $420 \mathrm{HV}$ by zone heating and cooling mold methods. George et al. [11] successfully trial-produced a hot-stamped B-pillar with gradient performance by controlling the cooling of the die area. The results show that the hardness is about 244-260 HV in the hot zone and approximately $460 \mathrm{HV}$ in the cold zone. Wang et al. [12] investigated the influence of annealing temperature on the mechanical properties of boron steel and produced parts with tailored properties using partial annealing. At the same time, a series of advanced constitutive material models have been proposed for hot-stamping simulation of boron steel with tailored properties. Eller et al. [13] established a constitutive model of boron steel with tailored properties and validated the proposed plasticity and fracture model using a tapered tensile test specimen with a hardness transition zone. Li et al. [14-16] established the austenite transformation model to describe the austenitization of boron steel under complicated thermal conditions and extended a set of viscoplastic constitutive damage equations to model the deformation of boron steel in multiple phase states. Tang et al. [17] established a coupled thermo-mechanical-metallurgical numerical model for the tailored tempering process of 22MnB5 sheets, and verified the reliability of the model by using the thickness and microstructure test results of B-pillar stiffeners, accurately simulating the Vickers hardness distribution and microstructural evolution of a U-channel part. Hippchen et al. [18] developed a material model considering the diffusionless and diffusion-controlled kinetics of phase transformation for the prediction of the part geometry and mechanical properties of indirect hot-stamped car body parts with tailored properties. At present, in the field of hot stamping with tailored properties, many scholars focus on intrinsic strategy control, phase transformation, structure simulation, formability and so on [19]. However, only hardness tests and three-point bending tests are usually used to evaluate the strength and energy absorption performance of parts with tailored properties [20,21]. These tests lack the characteristic analysis, mechanism research and sufficient experimental demonstration for the re-deformation of the tailored parts. Digital image correlation (DIC) technology has been increasingly applied in the quantitative measurement of deformation fields, and has unique advantages in the non-uniform strain measurement of gradient materials. Paweł J. Romanowicz et al. [22] evaluated the feasibility and reliability of digital image correlation (DIC) system for engineering and science purposes. The results show that the application of DIC with a common digital camera can be effectively applied 
for the analysis of the evolution of plastic zones for high-strength steels. Ab Ghani et al. [23] compared the different methods of determining mechanical properties of a hybrid composite under tensile loading using a strain gauge and the DIC technique. They observed that the DIC method is reliable in determining mechanical properties of a hybrid composite. Ramazani [24] studied the microscopic deformation and fracture of DP600 dual-phase steel using electron backscattered diffraction (EBSD) measurements and the DIC technique. Li et al. [25] evaluated whole-field strain distribution and crack propagation/evolution of carbon fiber reinforced plastic (CFRP) laminate using the digital image correlation technique under tensile loading. In this paper, $22 \mathrm{MnB} 5$ was used as the material, and a new strategy of local induction heating and press hardening was used for the hot stamping of boron steel parts with tailored properties. The resulting microstructure, from the hard zone to the soft zone, shows a gradient distribution of martensite phase, multiphase and initial phase. The gradient structure was characterized and analyzed, and the re-deformation characteristics of different phase zones were studied by EBSD measurements and DIC technology, which verified that hot-stamping parts with tailored properties meet the function of a hard zone for anti-collision and a soft zone for energy absorption. The results of this research perfect the theory and application of hot stamping with tailored properties, and form a more complete closed-loop system.

\section{Preparation of Hot-Stamping Parts with Tailored Properties}

\subsection{Preparation Processing}

In this paper, differential heat treatment of the blank prior to forming is used to prepare hot-stamped parts with tailored properties. Like traditional hot stamping, tailored hot stamping consists of heating, transferring, forming and cooling. The concept of the selective heating strategy is to adjust the local mechanical properties by means of austenite transformation control in the heating step of the hot-stamping process [26]. The mechanism of the strategy is illustrated in Figure 1. In the differential heat treatment of a boron steel blank, there are three phase regions: the full austenite region, the transition region and the initial phase region [27]. The hard zone is heated to the austenite temperature range and is fully austenitized by heat preservation, whereas the soft zone is heated to the middle temperature, retaining its initial phase of boron steel, while partial austenitization occurs in the transition zone at a critical temperature. After full quenching, martensitic transformation occurs in the high-temperature region, resulting in a hard region with high strength, and the initial phase remains in the middle temperature range, resulting in a soft region with high plasticity. The transition zone is mainly composed of martensite, retained austenite and initial phase. The length and microstructure distribution of the transition zone depend on the temperature gradient heated on both sides.

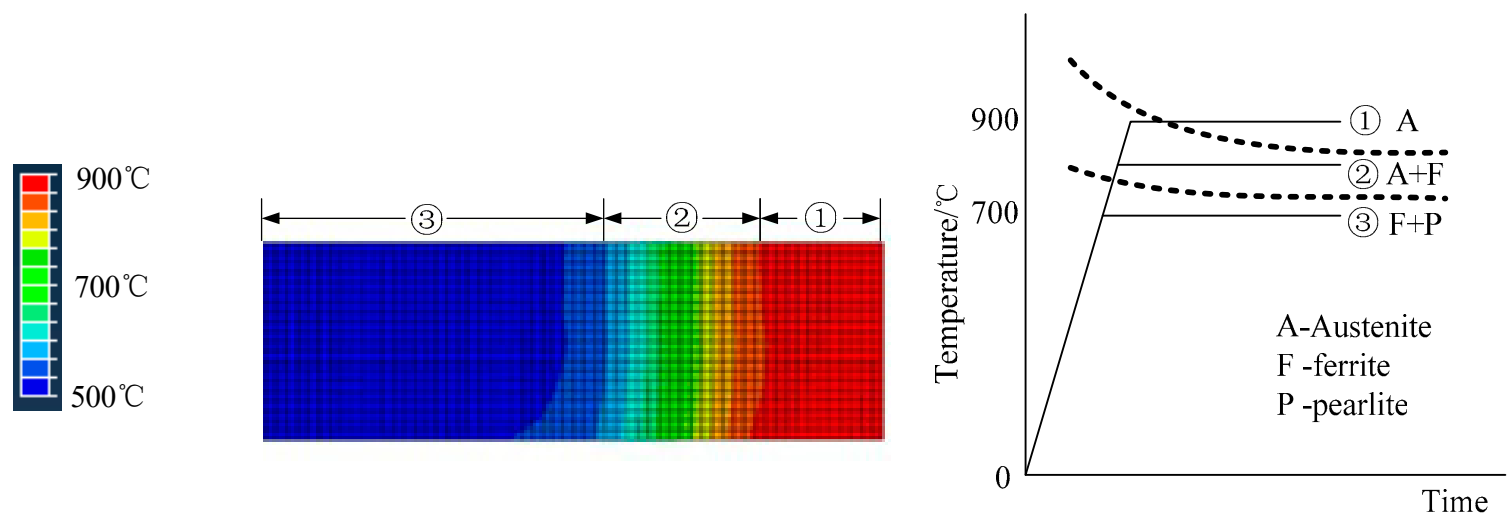

Figure 1. Strategic mechanism of selective heating and press hardening. 


\subsection{Differential Induction Heating Experiment}

The material used in this paper was cold-rolled 22MnB5 boron steel with a thickness of $1.4 \mathrm{~mm}$ provided by Maanshan Iron and Steel Group Co., Ltd. The initial microstructure contained a mixture of ferrite and pearlite. The chemical composition of the investigated steel is listed in Table 1 . A $75 \mathrm{~mm}$ $\times 160 \mathrm{~mm}$ rectangular boron steel plate was partly induction heated above $900{ }^{\circ} \mathrm{C}$ by induction heating using an experimental device with an oscillating power of $15 \mathrm{kV}$ and a 50-mm-diameter induction coil. The distance was $6 \mathrm{~mm}$ from the induction coil to the sheet. The induction heating experimental device is shown in Figure 2. Figure 3 shows the measurement results of the non-uniform temperature field of the induction heated specimen by infrared thermal imaging. It can be seen that, due to the edge effect, the plate specimen is heated from the outer ring along the winding direction of the coil. The temperature rises rapidly and the plate specimen presents an obvious temperature gradient along the diameter direction of the circle. The experimental results show that the non-uniform temperature field of the boron steel plate can be established by induction heating, and the average heating rate is $68-88^{\circ} \mathrm{C} / \mathrm{s}$. The central temperature of the plate can reach the Curie temperature in 8-10 s, and the maximum heating rate can reach $200^{\circ} \mathrm{C} / \mathrm{s}$. The high-temperature zone (austenite phase) of $\Phi 50 \mathrm{~mm}$ and the annular low-temperature zone (original initial phase) with an inner diameter of $\Phi 50 \mathrm{~mm}$ and an outer diameter of $\Phi 75 \mathrm{~mm}$, were obtained experimentally. The temperature distribution of the plate specimen is shown in Figure 4.

Table 1. Chemical compositions of 22MnB5 (mass \%).

\begin{tabular}{cccccccc}
\hline C & Mn & Cr & Si & B & P & S & Al \\
\hline 0.225 & 1.24 & 0.163 & 0.256 & 0.003 & 0.013 & 0.003 & 0.030 \\
\hline
\end{tabular}

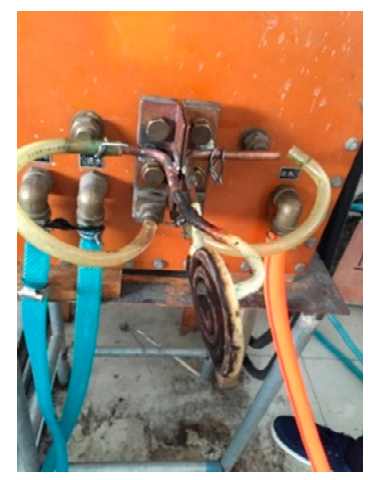

Figure 2. Induction heating experimental device.

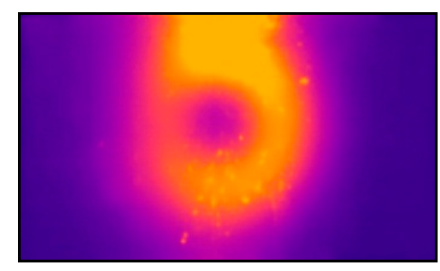

(a)

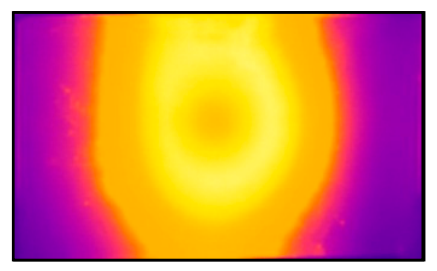

(b)

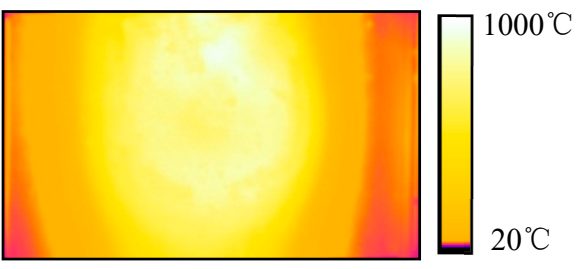

(c)

Figure 3. Temperature variation of induction heating workpiece: (a) in the beginning; (b) in the middle; (c) at the end. 


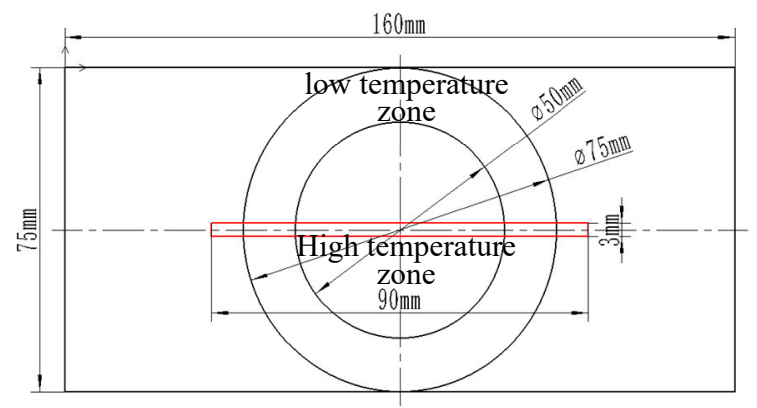

(a)

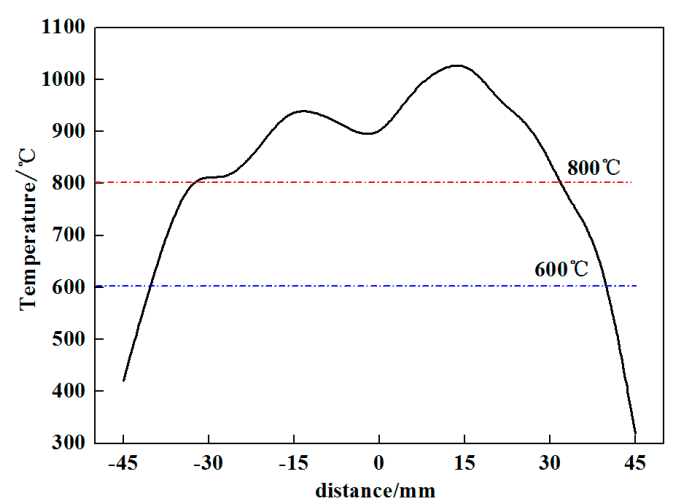

(b)

Figure 4. Temperature distribution of sheet after selective heating. (a) Top view: the red rectangle is the axial temperature measurement area. This area is taken as a microstructure characterization sample; (b) central axis: temperature is measured along horizontal axis.

\section{Characterization of Hot-Stamping Parts with Tailored Properties}

Hardness testing and metallographic testing were conducted to assess the microstructure distribution and load-bearing performance, respectively. This was performed by cutting a beam $90 \mathrm{~mm}$ long and $3 \mathrm{~mm}$ wide symmetrically along the horizontal axis. The sampling location is shown in the red area of Figure 4a. The hardness was measured every $0.2 \mathrm{~mm}$ along the axis by a microhardness tester. In Figure 5, Vickers hardness values are plotted on a length scale, where the bar mid-length is taken as the origin. The results show that the hardness is high in the middle of the specimen and the value of the high-strength zone is from $440 \mathrm{HV}$ to $550 \mathrm{HV}$, and the length is from -21.66 to $27.89 \mathrm{~mm}$, which is consistent with the heating range of the high-temperature zone. The high-temperature zone is fully austenitized in preheating and martensitic transformation occurs after quenching. The hardness fluctuation corresponds to the winding of the induction coil, which indicates that the faster the heating speed, the higher the hardness of the martensite. The ranges of the hardness value decrease rapidly in the transition zone, located from $3.73 \mathrm{~mm}$ on the left and $2.61 \mathrm{~mm}$ on the right, which has a graded multiphase microstructure. Away from the hot zone, the hardness of the low-hardness zone at both sides is $178-230 \mathrm{HV}$, and the hardness of the initial phase after heating is slightly higher than before. According to the hardness distribution, the sample shows a gradual structure gradient, which can be divided into three zones: the hard zone, the transition zone and the soft zone. The microstructure of each zone, observed by optical microscopy, is shown in Figure 6. The soft zone is the initial phase, with about $200 \mathrm{HV}$, which is the mixed structure of ferrite and pearlite. According to the calculation of the intercept method, the grain size is about $10 \mu \mathrm{m}$. The hard zone is martensite with a hardness above $440 \mathrm{HV}$, which is a large number of fine laths of about $0.15 \mu \mathrm{m}$. Figure $6 \mathrm{c}, \mathrm{d}$ show the microstructure of the transition zone with different hardness. The transition zone is composed of ferrite, residual austenite and martensite, an irregular crystal morphology. With the increase of martensite, the hardness increases gradually. 


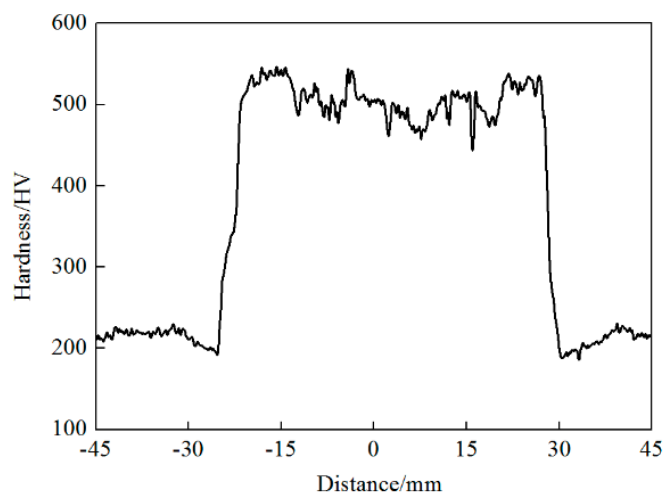

Figure 5. Hardness distribution.

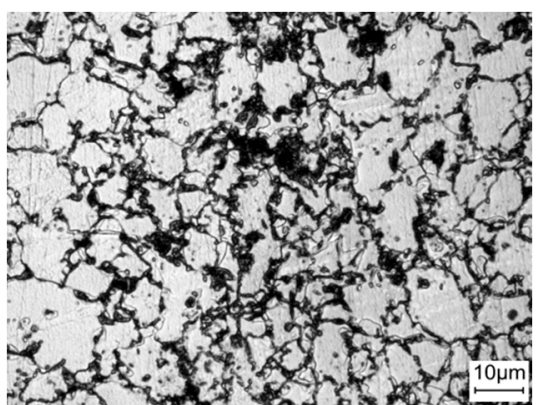

(a)

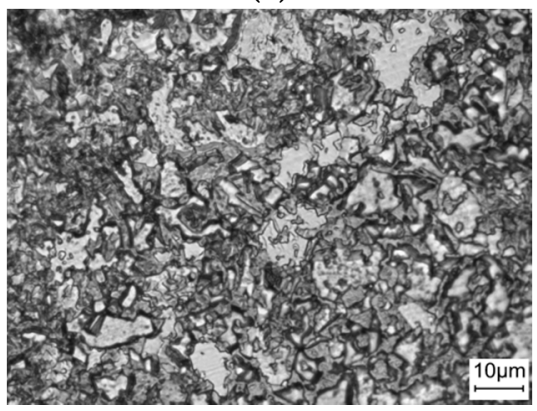

(c)

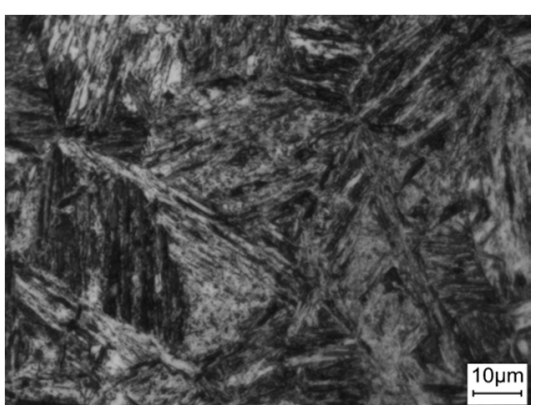

(b)

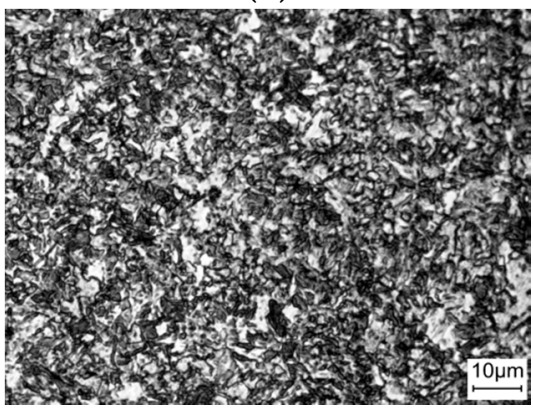

(d)

Figure 6. Optical metallographic (OM) photographs of different phase zones: (a) soft zone, $210 \mathrm{HV}$; (b) hard zone, $490 \mathrm{HV}$; (c) transition zone, $280 \mathrm{HV}$; (d) transition zone, $375 \mathrm{HV}$.

\section{The Re-Deformation Performance of Hot-Forming Parts with Tailored Properties}

\subsection{Experimental Method}

In this study, a non-contact full field strain testing system was used to evaluate the properties of the hot-stamped parts with tailored properties by zones based on DIC technology and the tensile testing machine, as shown in Figure 7. The non-contact full field strain testing system is mainly composed of hardware part and software part. The hardware part includes two charge coupled device (CCD) cameras (GS3-U3-51S5M, Point Grey, Richmond, BC, Canada) pan tilt, light source and computer, and the software part is VIC-3D by Correlated Solution company in the United States, composed of image acquisition system and data analysis and processing system. It is a powerful system for measuring and visualizing of shape, displacement and strain, movements and vibrations of surfaces in three dimensions. Firstly, a sample taken along the length direction of the hot-stamping parts with tailored properties was randomly speckle treated, as shown in Figure 8, and the microstructure of the tensile samples showed a symmetrical distribution of initial phase, multiphase and martensite. Before the experiment started, it was necessary to calibrate the whole field strain measurement system to improve the measurement quality. Two CCD cameras were set up at an angle between $15^{\circ}$ and 
$60^{\circ}$ to ensure that the specimen is full in the whole field of vision with reasonable tensile allowance. Speckle quality assessment function was used to focus the camera and adjust the brightness and exposure time, and then selected the appropriate correction plate through the calibration images function to make sure the size of the correction plate should be about $80 \%$ of the camera's view. About 25 photos of the calibration plate and the specimen in different relative positions were taken as image correction samples, through VIC-3D software (CSI, VIC-3D 7), the calibration results are analyzed and processed, and the red error reported pictures are deleted to ensure that there are no less than 15 valid pictures. If the system scores pass, the calibration is successful. Otherwise, this step needs to be repeated until the calibration is qualified. After the above steps were completed, the tensile test was carried out on the tensile testing machine at the strain rate of $0.1 \mathrm{~s}^{-1}$ until the specimen is broken, and 192 speckle images were collected in the whole process. The images were imported into the data analysis and processing software. Taking the initial state as a reference image, the analysis area of $80 \mathrm{~mm}$ was selected. In the DIC analyses, and the following parameters were used: grid size, 45-45 pixels; and grid overlapping, 8 pixels. And the normal strain, shear strain and other information are obtained by software calculation. The characteristics of strain in different micro regions were analyzed with an scanning electron microscope (SEM), based on the EBSD technique. The samples for EBSD were cut from before and after deformation of the workpiece and were prepared by mechanical polishing, followed by electropolishing, to remove the deformed layer on the surface that formed during the mechanical polishing. The EBSD scans of $60 \times 60 \mathrm{~m}$, with a step size of $0.06 \mu \mathrm{m}$, were performed in an SEM system operated at $20 \mathrm{kV}$. The post-processing of the scanned data was carried out using TSL OIM software $($ EDAX, 7.3.0 × 86).

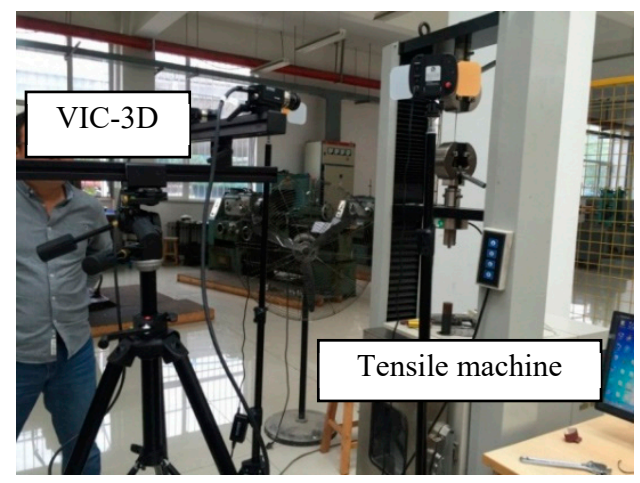

Figure 7. Full field strain experimental platform for tensile test.
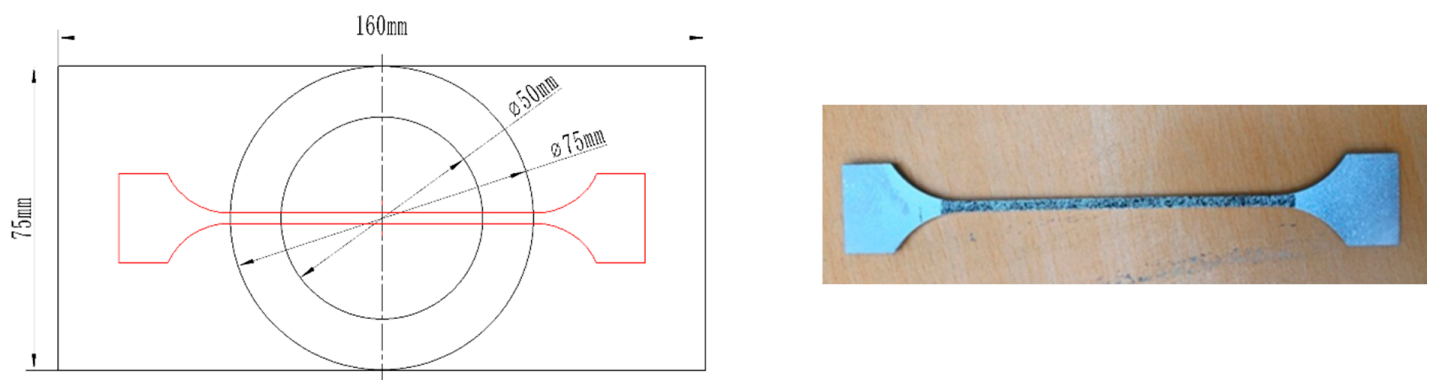

Figure 8. Tensile specimen after speckle treatment.

\subsection{Full Field Strain Analysis of Tensile Deformation}

Figure 9 is a strain cloud chart with time collected by the VIC-3D system, in which the black line is the isostrain line. At the beginning of the test (Figure 9a), the isostrain lines were uniformly and randomly distributed, and the specimen was in the stage of elastic deformation. As the tension progressed, the specimen began to yield and local plastic deformation occurred (Figure 9b) and the distribution of isostrain lines was obviously uneven (Figure 9c). The plastic deformation was 
concentrated on both sides in the initial phase zone and the martensite area in the middle was basically free of deformation. The deformation areas on both sides expanded to the far end of the test piece asymmetrically, due to the inhibition of the martensite phase in the middle (Figure 9d). When the tensile stress reached $550 \mathrm{MPa}$ (Figure 9e), which is close to the maximum tensile strength of the ferrite phase, local necking of the specimen occurred in the initial zone on the side of the specimen. At 192 steps (Figure 9g), the local strain reached 0.81, and a macrofracture occurred in the strain concentration area, shown by the white dotted box.

The distribution of the strain in different zones is shown in Table 2. The virtual extensometer was added to obtain the strain curve of the total and the different local zones by VIC-3D post-processing software, as shown in Figure 10. It was found that the re-deformation process of the hot-stamped part with tailored properties is an equal-stress process. During the plastic deformation stage, there is an obvious strain distribution phenomenon, according to the different microstructure morphologies of the specimen. In the initial phase zone, the maximum strain in the upper side before necking was 0.32 , and the strain in the lower side was 0.14 , showing a good deformation energy absorption effect. The martensitic zone in the middle was basically undeformed, and the strain was not more than 0.006 . The total strain of the specimen was contributed mainly by the deformation of the initial phase zone on both sides. This proves that the high-strength zone provides protection support and the low-strength zone takes on the role of energy absorption.

Table 2. Local maximum strain in different regions of uniaxial tension.

\begin{tabular}{ccc}
\hline \multicolumn{1}{c}{ Specimen } & Martensitic Zone & Initial Phase Zone \\
\hline Step & 0.00065 & 0.001 \\
60 & 0.0019 & 0.00256 \\
90 & 0.00449 & 0.027 \\
120 & 0.00575 & 0.0625 \\
150 & 0.00576 & 0.129 \\
190 & 0.00576 & 0.81 \\
\hline
\end{tabular}




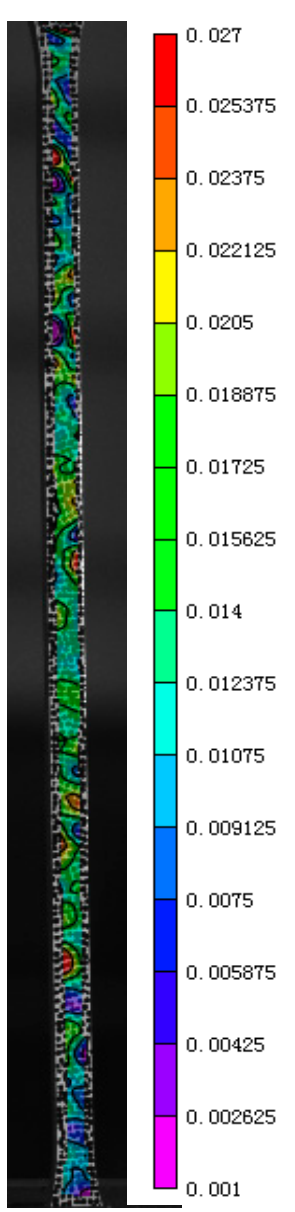

(a)

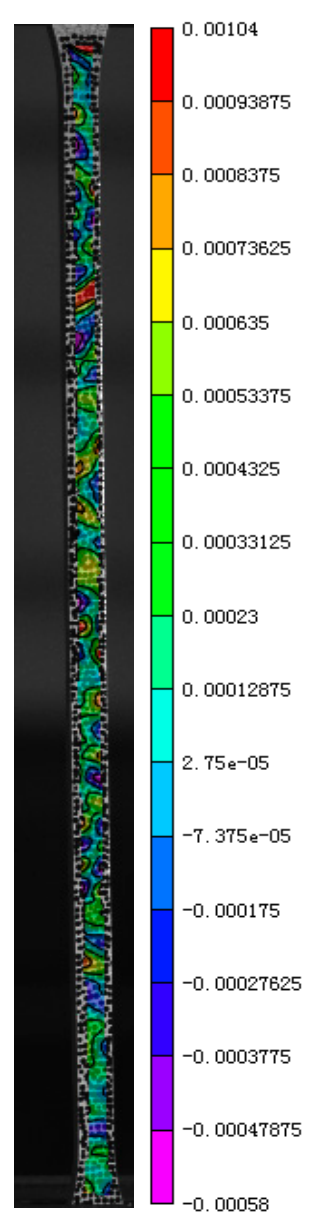

(b)

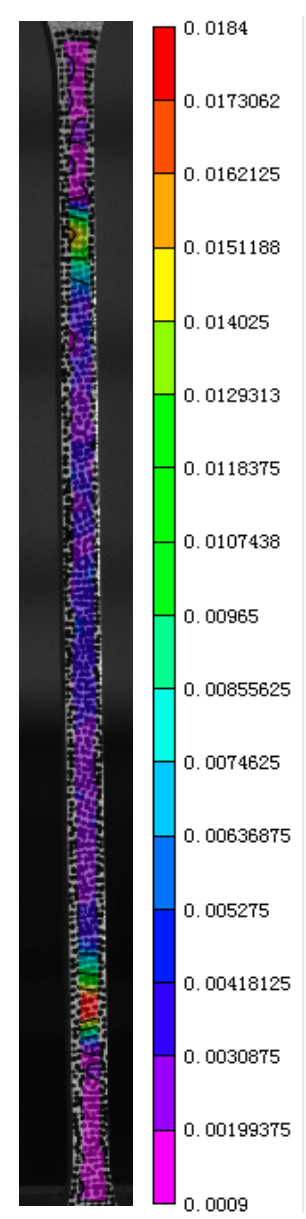

(c)

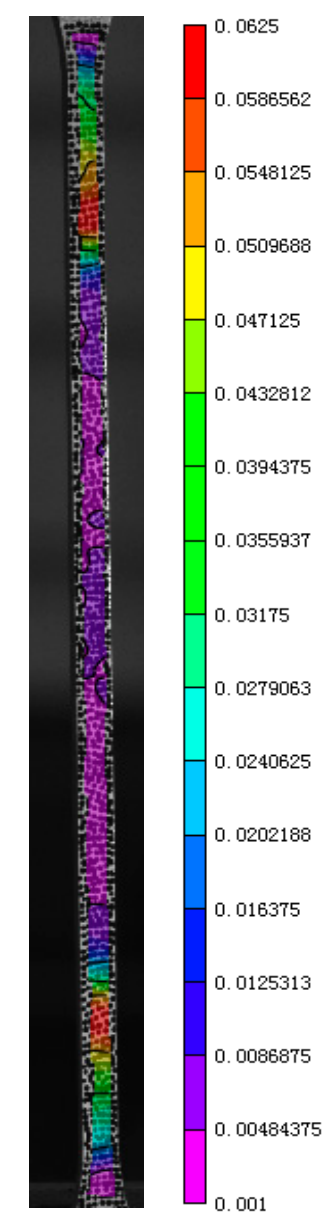

(d)

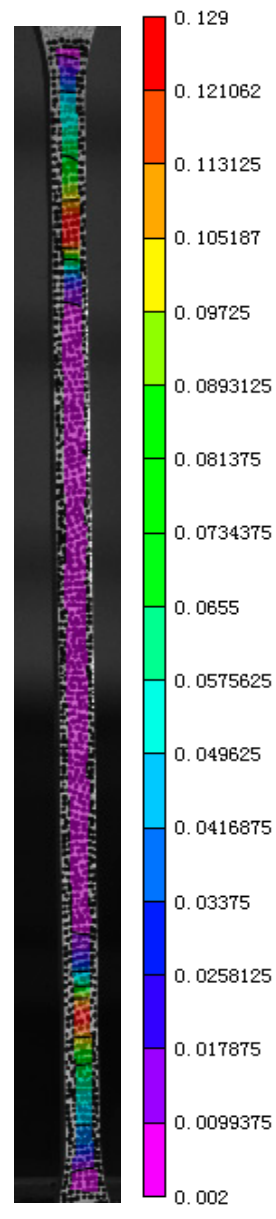

(e)

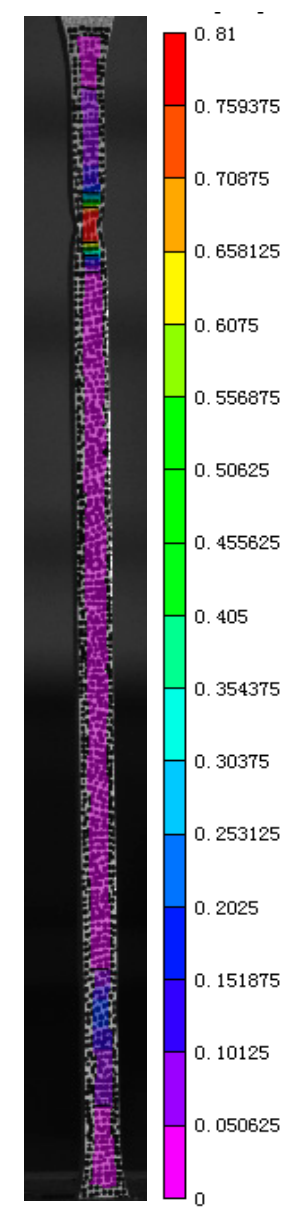

(f)

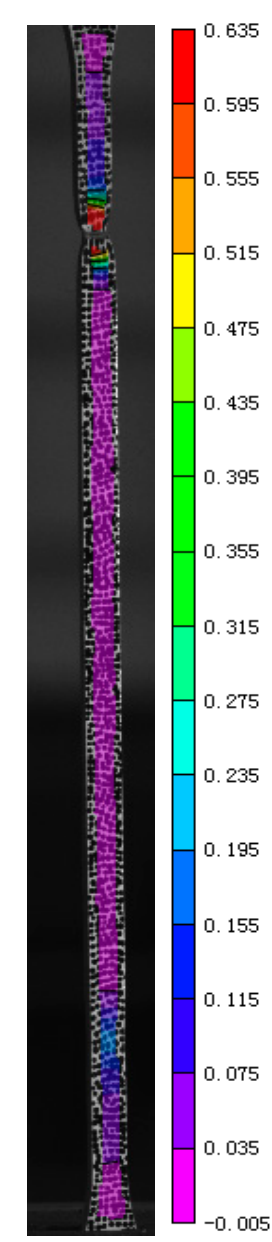

(g)

Figure 9. Cloud map of full-field equivalent strain change with time in tensile test: (a) Step 40; (b) Step 60; (c) Step 90; (d) Step 120; (e) Step 150; (f) Step 190; (g) Step 192. 


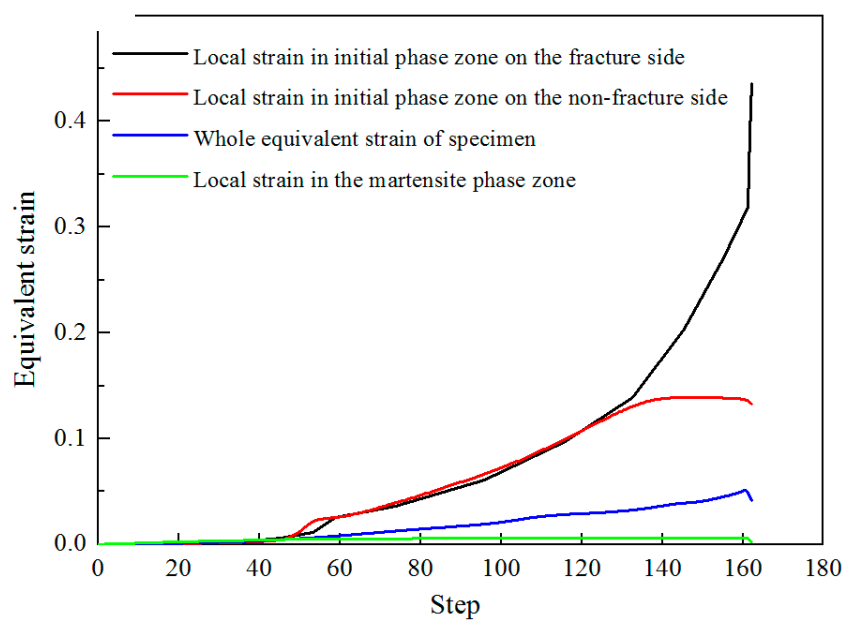

Figure 10. Equivalent strain in different phase regions by virtual extensometer.

\subsection{Electron Backscattered Diffraction (EBSD) Analysis of Hot-Stamped Parts with Tailored Properties Before and After Deformation}

EBSD scanning was carried out on the samples with tailored properties to study the microstructure morphology by grain morphology, grain size, grain orientation and micro-area strain. Figure 11 shows EBSD test results of different phase zones of hot stamping with tailored properties before the tensile test, including the superposition maps of the inverse pole figure (IPF) and image quality (IQ), as well as the statistical distribution map of grain size. The IPF maps are observed with the normal direction of the observation surface $\{001\}$ as the reference direction. Blue, red and green represent the orientations of $\{111\},\{001\}$ and $\{101\}$ respectively. It can be seen that the microstructure of the soft zone reveals a random texture, and the average grain size is $8.16 \mu \mathrm{m}$, with $9.8 \mu \mathrm{m}$ being the most common grain size, accounting for $18.25 \%$. The microstructure of martensite in the hard zone is multi-scale, consisting of packets, blocks and laths. The laths are thin and most of them have the same orientation.

Figure 12 shows the IPF and IQ superposition maps with different deformation ratios of the hot-stamping part with tailored properties after the tensile test. The specimens are taken at $1 \mathrm{~mm}$, $3 \mathrm{~mm}, 7 \mathrm{~mm}, 10 \mathrm{~mm}$ and $12 \mathrm{~mm}$ away from the fracture, where the corresponding strain is $0.607,0.04$, $0.0064,0.0048$ and 0.0039 , respectively. It can be seen that with the increase of deformation, the ferrite grains are obviously elongated and flattened, and there is an obvious color gradient distribution inside the grains, which means that the grains have undergone obvious plastic deformation. Figure $12 \mathrm{~d}$ is the transition zone. The lattice distortion is serious, and the image quality is poor because of the multiphase mixed structure of lath martensite and massive ferrite. The martensitic zone (Figure 12e) displays almost no change of contrast, which means that the deformation does not extend to this zone. Figure 13 is a comparison diagram of grain size under different deformation ratios. It was found that, with the increase of plastic strain, the grain size after deformation was gradually refined. The average grain size of the initial phase is $7.42 \mu \mathrm{m}$, with a deformation ratio of $4 \%$. When the average grain size is $3.43 \mu \mathrm{m}$, the deformation ratio increases to $60 \%$, a difference of $58 \%$.

Figures 14 and 15 show the misorientation distribution of the grain boundaries before and after deformation in the initial phase zone and the martensite zone, respectively. It can be seen from Figure 14 that before deformation, most of the grain boundaries are high-angle grain boundaries, i.e., more than $15^{\circ}$, and low-angle grain boundaries account for only $13.5 \%$. The increase of deformation causes the number of low-angle grain boundaries to increase continuously, which is a result of the increase in dislocation density. When the deformation ratio increases from $4 \%$ (Figure $14 \mathrm{~b}$ ) to $60 \%$ (Figure 14c), the low-angle grain boundary percentage increases from $20.9 \%$ up to $63.3 \%$. Martensite with multi-scale characteristics has a high dislocation density, as shown in Figure 15. Before the tensile test, the low-angle grain boundaries accounted for $27.5 \%$. The misorientation of grain boundaries was almost unchanged 
after tensile test, which indicates that there was no micro-strain in the martensite phase zone during the uniaxial tension process.

We used the kernel average misorientation (KAM) to show the local misorientation between neighbor grains, which can be expressed as the collective dislocation structure in the grains [28]. It is usually used to estimate the residual strain and plastic deformation. In this analysis, the colors of blue to red represent the KAM value of misorientation in the range of $0^{\circ}$ and $5^{\circ}$, and misorientation values exceeding a threshold value of $5^{\circ}$ were excluded from the KAM calculation. Figures 16 and 17 show the KAM distributions under different conditions in the initial phase zone and the martensite phase zone. As shown by Figure 16, most regions in 22MnB5 steel exhibit low KAM values, as does the initial phase zone of the hot-stamped part with tailored properties, which means that residual stress does not increase due to selective heating and press hardening. However, with increasing deformation, the density of areas with high KAM values increases. When the deformation reaches $4 \%$ (Figure 16c), a green color around the grain boundaries can be clearly observed. There are wide regions of low KAM values, surrounded by regions of higher KAM values. KAM maps of samples deformed to $60 \%$ strain (Figure 16d) demonstrate a significant increase in local misorientation in the grain boundary region, appearing to consist largely of yellow regions, and even displaying red regions. In Figure 17, high misorientation is indicated in the martensite phase zone because the lattice distortion is large, whereas the lath interiors do not display any significant misorientation change before and after tensile deformation, which means that the tensile deformation does not cause micro-strain in the martensite zone. Therefore, the micro-strain in the re-deformation of the hot-stamped part with tailored properties has obvious regional characteristics according to the microstructure.

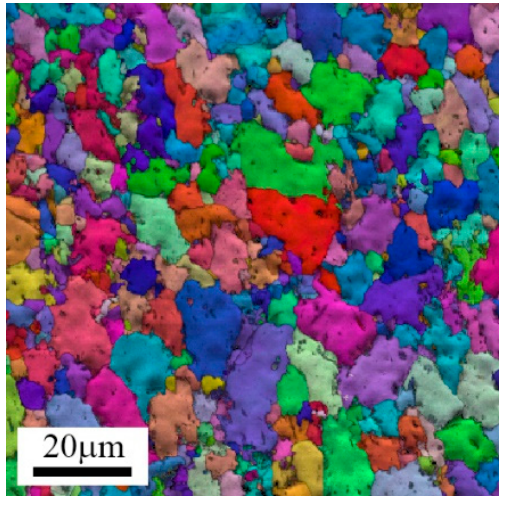

(a)

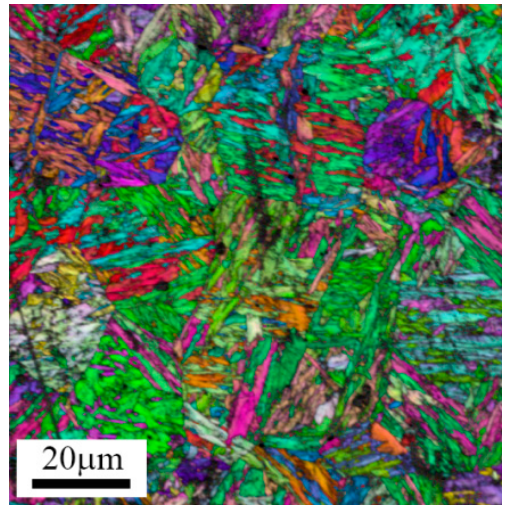

(c)

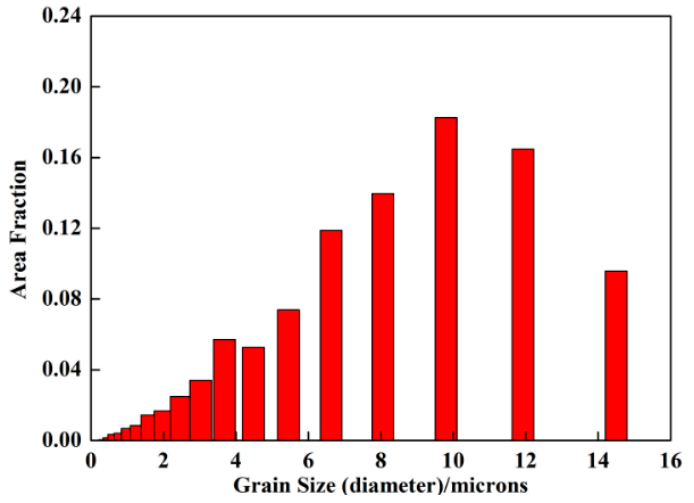

(b)

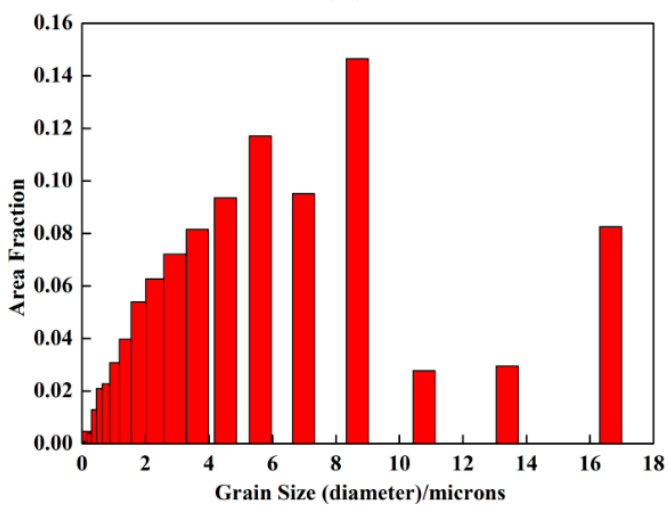

(d)

Figure 11. Electron backscattered diffraction (EBSD) analysis of a hot-stamped part with tailored properties. (a) Inverse pole figure (IPF) and image quality (IQ) diagram of initial phase zone; (b) grain size distribution of initial phase zone; (c) IPF and IQ diagram of martensite phase zone; (d) grain size distribution of martensite phase zone. 


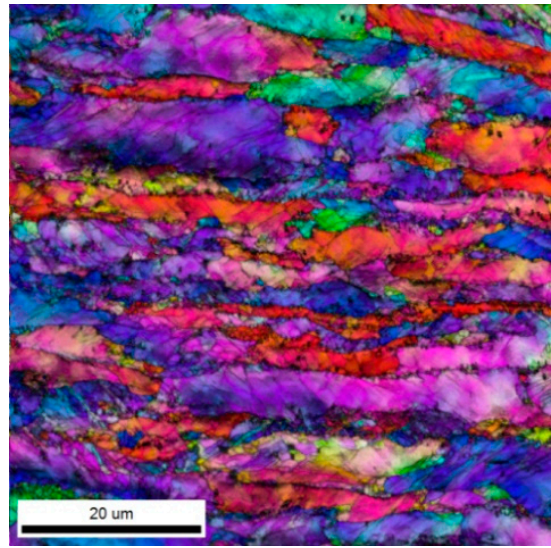

(a)

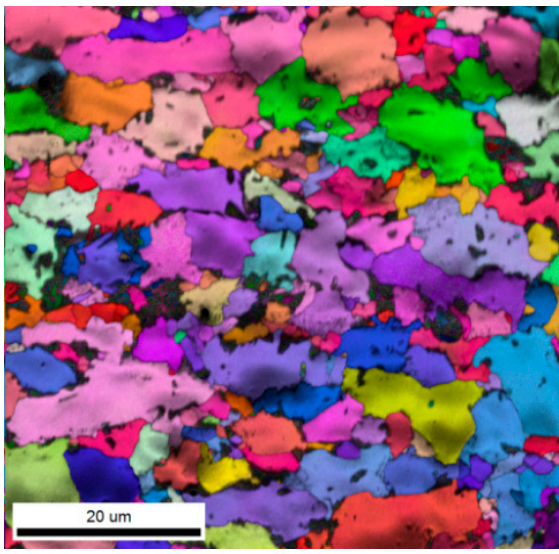

(c)

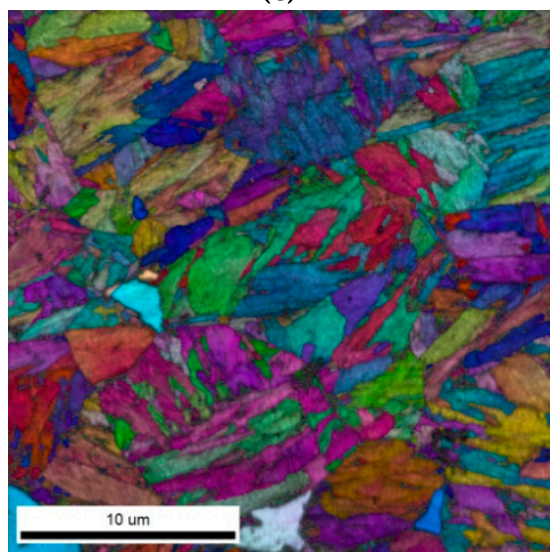

(e)

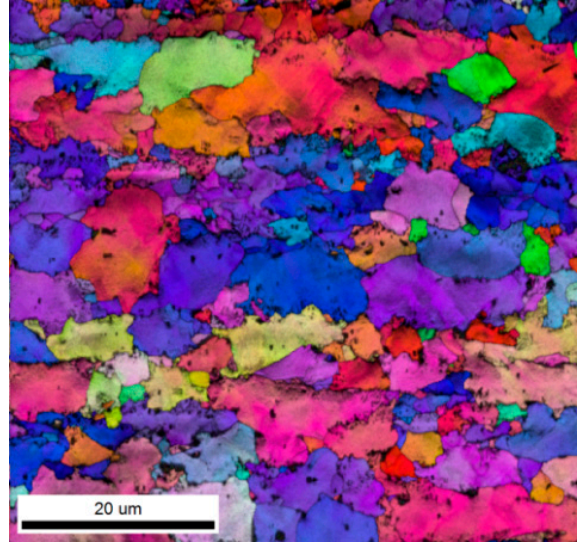

(b)

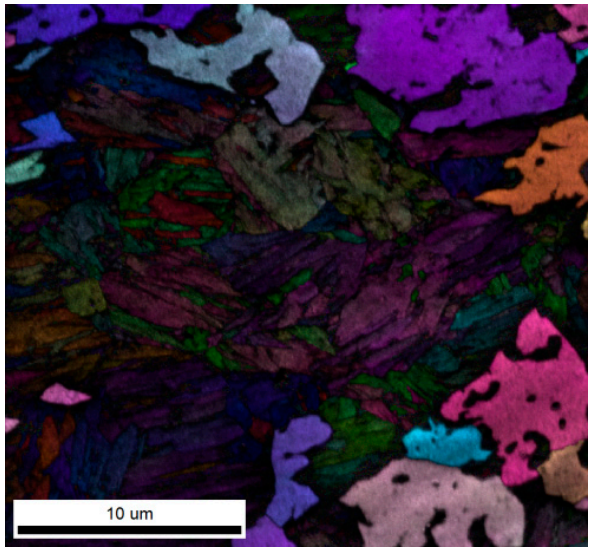

(d)

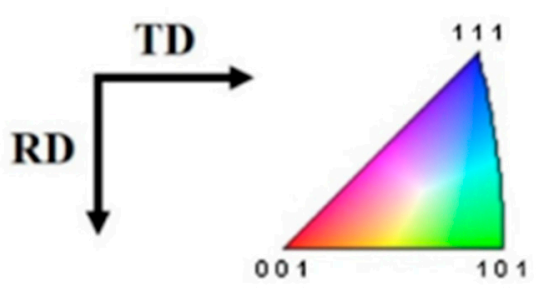

(f)

Figure 12. IPF + IQ diagram of a hot-stamped part with tailored properties with different deformation ratios after a tensile test; (a) $\varepsilon=0.607 ;(\mathbf{b}) \varepsilon=0.04 ;(\mathbf{c}) \varepsilon=0.0064 ;(\mathbf{d}) \varepsilon=0.0048 ;(\mathbf{e}) \varepsilon=0.0039 ;$ (f) different colors represent different orientations: blue represents the orientation of $\{111\}$; red represents the orientation of $\{001\}$; green represents the orientation of $\{101\}$. 


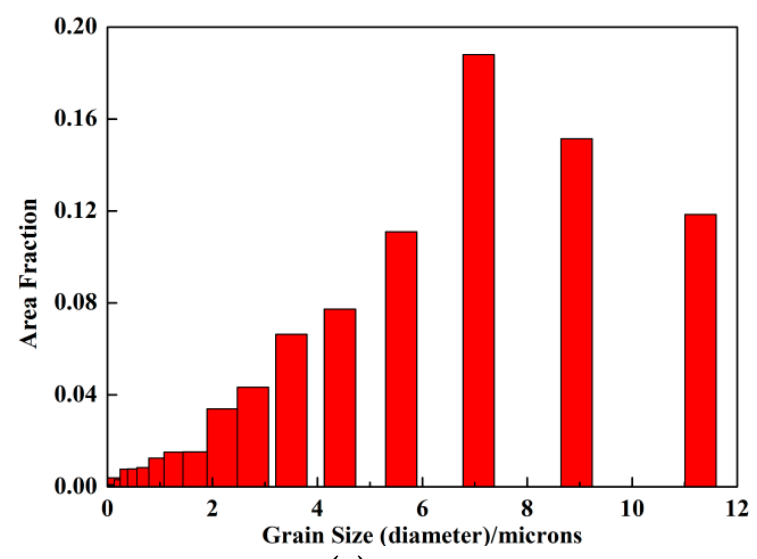

(a)

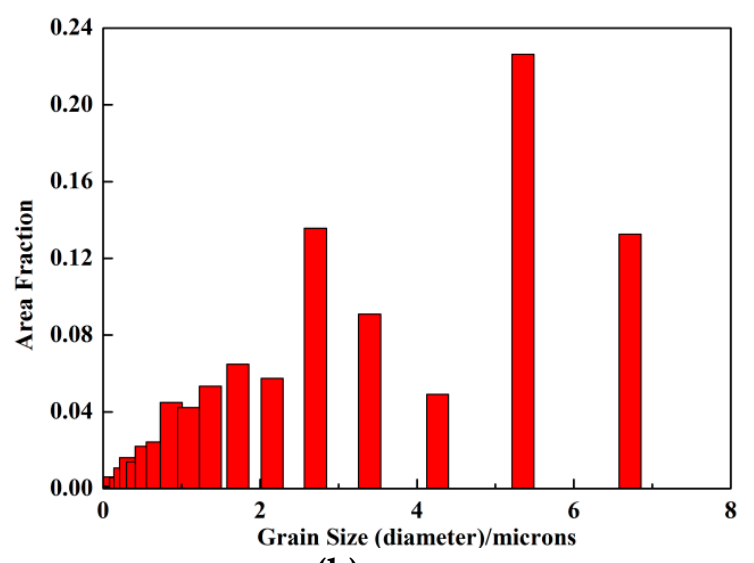

(b)

Figure 13. Statistical distribution of grain size in different deformation ratios; $(\mathbf{a}) \varepsilon=0.607 ;(\mathbf{b}) \varepsilon=0.04$.

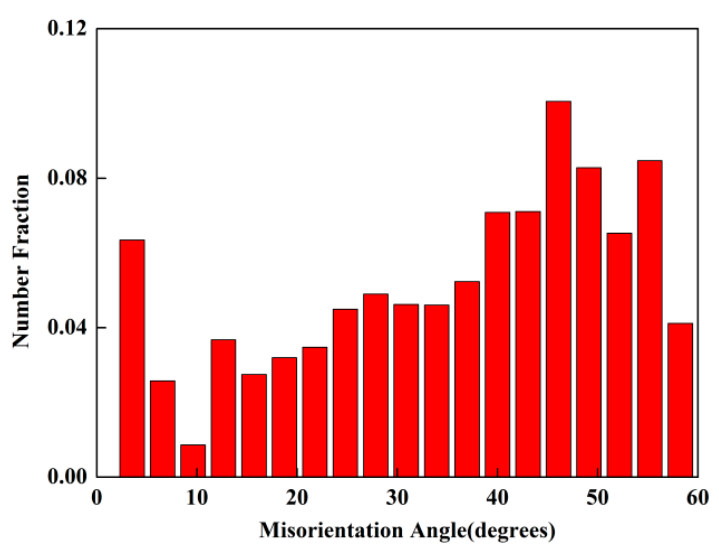

(a)

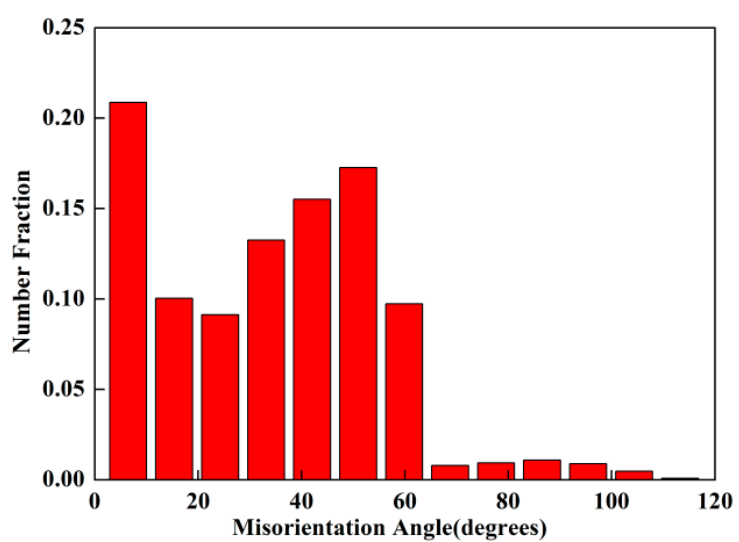

(b)

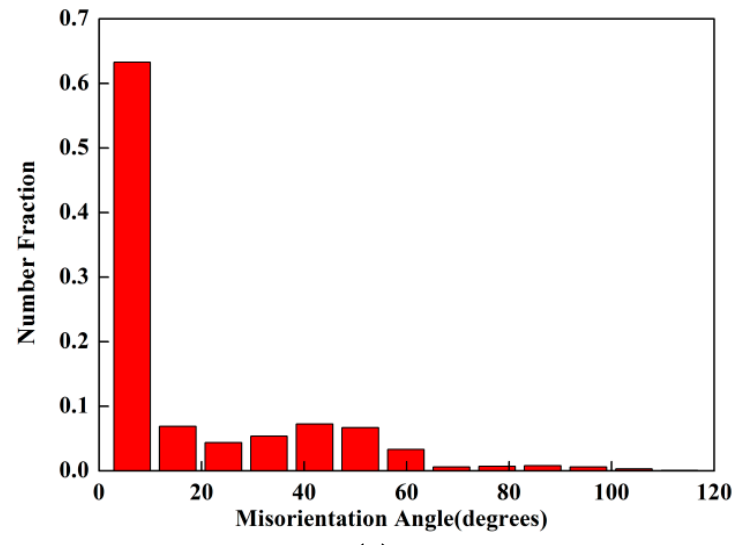

(c)

Figure 14. Misorientation distribution of grain boundaries in the initial phase zone with different deformation ratios; (a) $\varepsilon=0$; (b) $\varepsilon=0.04$; (c) $\varepsilon=0.607$. 


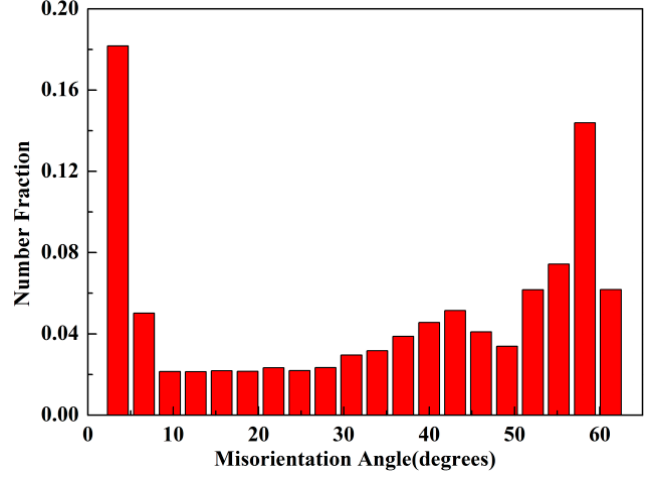

(a)

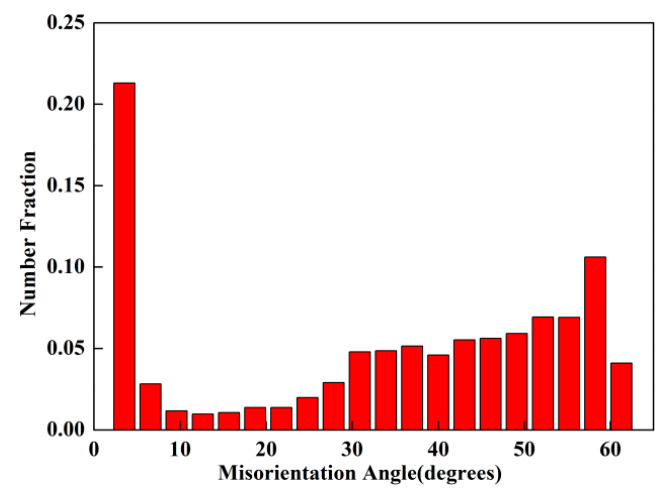

(b)

Figure 15. Misorientation distribution of grain boundaries in the martensite phase zone; (a) before tensile test; (b) after tensile test.

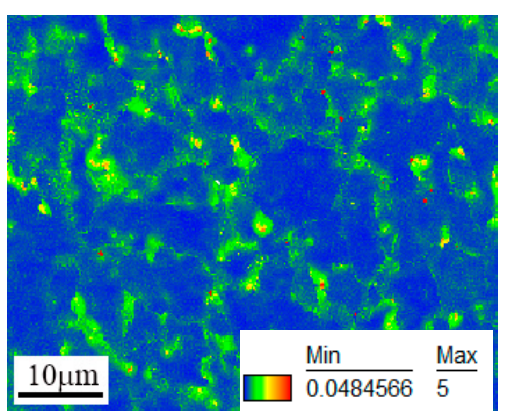

(a)

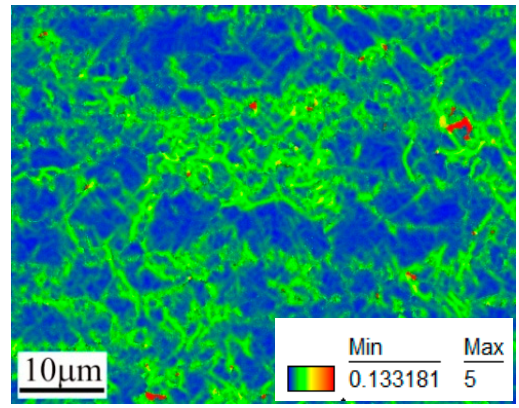

(c)

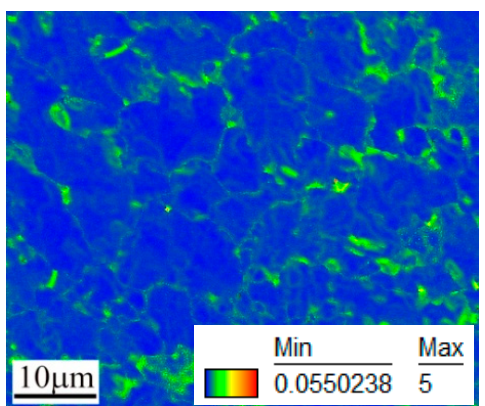

(b)

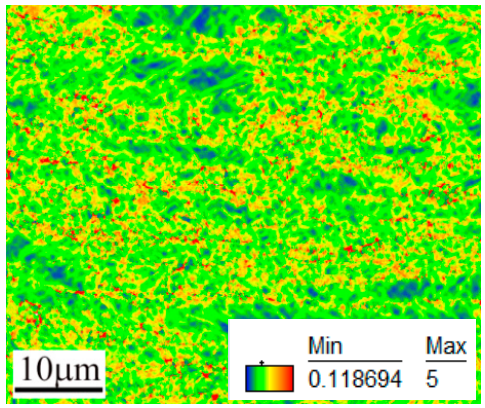

(d)

Figure 16. Kernel average misorientation (KAM) maps of different conditions in the initial phase zone; (a) initial sheet; (b) initial phase zone of hot stamping parts with tailored properties; (c) $\varepsilon=0.04$; (d) $\varepsilon=0.607$.

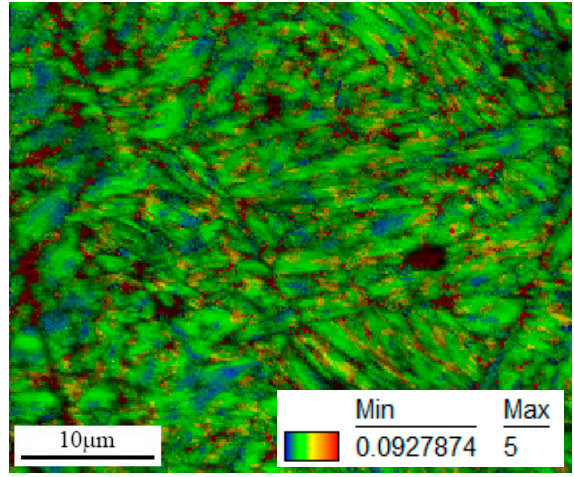

(a)

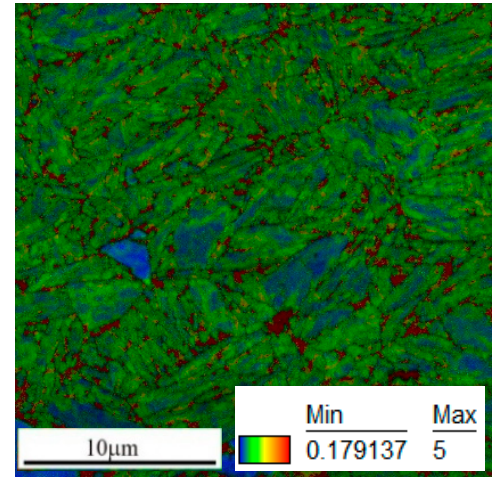

(b)

Figure 17. KAM maps of martensite phase zone undeform and fractured samples. (a) Martensite phase zone of hot-stamped parts with tailored properties; (b) martensite phase zone after fracture. 


\section{Conclusions}

In this work, hot-stamped parts with tailored properties were obtained by local induction heating and press hardening. The microstructure, from the hard zone to the soft zone, shows a gradient distribution of martensite, multiphase and initial phase, with the hardness ranging from $550 \mathrm{HV}$ to $180 \mathrm{HV}$. Through the macro- and micro-analysis of strain by a tensile test of parts with tailored properties, it can be shown that the re-deformation of the gradient specimen is a process of equal stress, and there are obvious strain distribution characteristics in the re-deformation process, which meet the stress distribution principle of multiphase steel. The initial phase zone results in deformation and energy absorption; the maximum strain before necking reaches 0.32 , with a large number of low-angle grain boundaries forming in the deformation process. The proportion of small-angle grain boundaries increases from $13.5 \%$ before deformation to $63.3 \%$ after deformation, whereas the average grain size decreased from $8.15 \mu \mathrm{m}$ to $3.43 \mu \mathrm{m}$, and the density of areas with high KAM value shows an obvious increase. The martensite zone takes on the role of anti-collision protection; the maximum strain is only 0.006 before fracture, and the lath interiors do not display any significant misorientation change before or after tensile deformation. The experimental results show that the hot stamping of parts with tailored properties meets the function of a hard zone for anti-collision and a soft zone for energy absorption and can, therefore, fit the requirements of automobile anti-collision parts.

Author Contributions: L.K. and Y.P. proposed ideas and conceived, designed and performed the experiments; C.L. and L.K. analyzed the data; Y.P. contributed materials and the analysis tool; L.K. and C.L. wrote the original draft preparation; L.K. and Y.P. reviewed and edited. All authors have read and agreed to the published version of the manuscript.

Funding: This research was funded by Key project of the Natural Science Foundation of Hebei Province (E2017203161) and the Yanshan University Doctoral Fund (8190145).

Acknowledgments: Everyone who contributed to the article has been included among the authors.

Conflicts of Interest: The authors declare no conflict of interest.

\section{References}

1. Yi, H.; Chang, Z.; Cai, H. Ductility and Fracture Strain of Press-Hardening Steels. Acta Mech. Sin. 2020, $56,429-443$.

2. Mori, K.; Bariani, P.F.; Behrens, B.A. Hot stamping of ultra-high strength steel parts. CIRP Ann. Manuf. Technol. 2017, 66, 755-777. [CrossRef]

3. Merklein, M.; Wieland, M.; Lechner, M. Hot stamping of boron steel sheets with tailored properties: A review. J. Mater. Process. Technol. 2016, 228, 11-24. [CrossRef]

4. Feng, X.; Xiong, Z.; Hui, Z. A review on functionally graded structures and materials for energy absorption. Eng. Struct. 2018, 171, 309-325.

5. Peng, Y.; Liu, C.; Hao, L. Review of Performance Gradient Distribution Hot Forming Technology. J. Mech. Eng. 2013, 49, 148-156. [CrossRef]

6. Bao, L.; Nie, Q.; Wang, B.; You, X. Development of Hot Stamping Technology for High Strength Steel Parts with Tailored Properties. In Proceedings of the IOP Conference Series: Materials Science and Engineering, Chengdu, China, 22-25 March 2019; pp. 12-16.

7. Wilsius, J.; Tavernier, B.; Abou-Khalil, D. Experimental and numerical investigation of various hot stamped B-pillar concepts based on Usibor 1500P. In Proceedings of the 3rd International Conference on Hot Sheet Metal Forming of High-Performance Steel, Kassel, Germany, 13-17 June 2011; pp. 424-435.

8. Mu, Y.H.; Wang, B.Y.; Zhou, J. Hot Stamping of Boron Steel Using Partition Heating for Tailored Properties: Experimental Trials and Numerical Analysis. Metall. Mater. Trans. A 2017, 48, 5467-5479. [CrossRef]

9. Mu, Y.H.; Wang, B.Y.; Zhou, J. Heating Parameters Optimization of Hot Stamping by Partition Heating for Tailored Properties. ISIJ Int. 2017, 57, 1442-1450. [CrossRef]

10. Svec, T.; Grüner, M.; Merklein, M. FE-simulation of the heat transfer by defined cooling conditions during the hot stamping process. Key Eng. Mater. 2011, 473, 699-706. [CrossRef] 
11. George, R.; Bardelcik, A.; Worswick, M.J. Hot forming of boron steels using heated and cooled tooling for tailored properties. J. Mater. Process. Technol. 2012, 212, 2386-2399. [CrossRef]

12. Wang, Z.J.; Liu, P.X.; Xu, Y.; Wang, Y.L.; Zhang, Y.S. Hot stamping of high strength steel with tailored properties by two methods. In Proceedings of the Procedia Engineering, Nogaya, Japan, 19-24 October 2014; pp. 1725-1730.

13. Eller, T.K.; Greve, L.; Andres, M.T. Plasticity and fracture modelling of quench-hardenable boro.n steel with tailored properties. J. Mater. Process. Technol. 2014, 214, 1211-1227. [CrossRef]

14. Li, N.; Lin, J.; Balint, D.S. Modelling of austenite formation during heating in boron steel hot stamping processes. J. Mater. Process. Technol. 2016, 237, 394-401. [CrossRef]

15. Li, N.; Lin, J.; Dean, T. Materials Modelling for Selective Heating and Press Hardening of Boron Steel Panels with Graded Microstructures. Procedia Eng. 2014, 81, 1675-1681. [CrossRef]

16. Li, N.; Lin, J.G.; Dean, T.A. Development of unified viscoplastic-damage model for crashworthiness analysis of boron steel safety components with tailored microstructures. Appl. Mech. Mater. 2015, 784, 8. [CrossRef]

17. Tang, B.; Li, C.; Zheng, W.; Huang, L.; Yuan, Z. Finite element model of hot stamping of tailor welded high strength steel and its experimental verification. J. Shanghai Jiaotong Univ. 2016, 50, 994-999.

18. Hippchen, P.; Lipp, A.; Grass, H. Modelling kinetics of phase transformation for the indirect hot stamping process to focus on car body parts with tailored properties. J. Mater. Process. Technol. 2016, 228, 59-67. [CrossRef]

19. Di Schino, A.; Alleva, L.; Guagnelli, M. Microstructure evolution during quenching and tempering of martensite in a medium C steel. Mater. Sci. Forum. 2012, 715-716, 860-865. [CrossRef]

20. Liang, W.; Wang, L.; Liu, Y. Hot stamping parts with tailored properties by local resistance heating. In Proceedings of the 11th International Conference on Technology of Plasticity, Nogaya, Japan, 19-24 October 2014; pp. 1731-1736.

21. Li, N.; Lin, J.; Dean, T.A. Concept Validation for Selective Heating and Press Hardening of Automotive Safety Components with Tailored Properties. Key Eng. Mater. 2014, 622-623, 1124-1131. [CrossRef]

22. Romanowicz, P.J.; Szybiński, B.; Wygoda, M. Application of DIC Method in the Analysis of Stress Concentration and Plastic Zone Development Problems. Materials 2020, 13, 3460. [CrossRef]

23. Ghani, A.F.A.; Mahmud, J. Material Characterization of Hybrid Composite: Experimental Using Strain Gauge/DIC with Finite Element Modelling Macro/Micro Scale. Key Eng. Mater. 2017, 740, 31-40. [CrossRef]

24. Ramazani, A.; Schwedt, A.; Aretz, A. Failure Initiation in Dual-Phase Steel. Key Eng. Mater. 2014, 586, 67-71. [CrossRef]

25. Li, M.; Gan, G.; Li, B. Whole-field strain analysis and strength prediction of fiber laser machined CFRP laminate at elevated temperature. Polym. Compos. 2020, 41, 2662-2672. [CrossRef]

26. Hein, P.; Wilsius, J. Status and Innovation Trends in Hot Stamping of USIBOR 1500 P. Steel Res. Int. 2008, 79, 85-91. [CrossRef]

27. Maikranz-Valentin, M.; Weidig, U.; Schoof, U. Components with optimised properties due to advanced thermo-mechanicalprocess strategies in hot sheet metal forming. Steel Res. Int. 2008, 79, 92-97. [CrossRef]

28. Schwartz, A.J.; Kumar, M.; King, W.E. Influence of Processing Method on the Grain Boundary Character Distribution and Network Connectivity. Mater. Res. Soc. Symp. Proc. 2000, 586, 3-14. [CrossRef]

(C) 2020 by the authors. Licensee MDPI, Basel, Switzerland. This article is an open access article distributed under the terms and conditions of the Creative Commons Attribution (CC BY) license (http://creativecommons.org/licenses/by/4.0/). 